\title{
RADIOCARBON DATING OF ALKENONES FROM MARINE SEDIMENTS: I. ISOLATION PROTOCOL
}

\author{
Naohiko Ohkouchi ${ }^{1,2} \bullet \mathrm{Li} \mathrm{Xu}^{3} \bullet$ Christopher M Reddy $^{1} \bullet$ Daniel Montluçon $^{1} \bullet$ \\ Timothy I Eglinton ${ }^{1,4}$
}

\begin{abstract}
The chemical and isotopic compositions of long-chain $\left(\mathrm{C}_{36}-\mathrm{C}_{39}\right)$ unsaturated ketones (alkenones), a unique class of algal lipids, encode surface ocean properties useful for paleoceanographic reconstruction. Recently, we have sought to extend the utility of alkenones as oceanic tracers through measurement of their radiocarbon contents. Here, we describe a method for isolation of alkenones from sediments as a compound class based on a sequence of wet chemical techniques. The steps involved, which include silica gel column chromatography, urea adduction, and silver nitrate-silica gel column chromatography, exploit various structural attributes of the alkenones. Amounts of purified alkenones estimated by GC/FID measurements were highly correlated with $\mathrm{CO}_{2}$ yields after sample combustion, indicating purities of greater than $90 \%$ for samples containing $\geq 100 \mu \mathrm{g} \mathrm{C}$. The degree of alkenone unsaturation $\left(U_{37}^{K^{\prime}}\right)$ also varied minimally through the procedure. We also describe a high-performance liquid chromatography (HPLC) method to isolate individual alkenones for molecular-level structural and isotopic determination.
\end{abstract}

\section{INTRODUCTION}

The isotopic characteristics of specific organic compounds preserved in aquatic sediments can provide important insights into the sources and biogeochemical cycling of organic matter in past and present environments (e.g. Hayes et al. 1990; Sessions et al. 1999; Sauer et al. 2001). In addition to information derived from stable isotopic compositions, molecular-level variations in the natural abundance of radiocarbon provide new insights into biogeochemical and sedimentological processes (Eglinton et al. 1997; Pearson et al. 2000; Petsch et al. 2001; Ohkouchi et al. 2002). For example, Ohkouchi et al. (2002) attributed significant ${ }^{14} \mathrm{C}$ age differences between planktonic foraminiferal carbonate and a suite of algal biomarker compounds in drift sediments from Bermuda Rise to lateral transport of the latter on fine-grained particles. The timing of sediment advection appears coupled with climate variations during the late Holocene.

Measurement of the stable isotopes of carbon, hydrogen, and nitrogen in nanogram quantities of individual compounds is possible via "on-line" or "continuous-flow" techniques to characterize components in gas chromatographic effluents (Hayes et al. 1990). In contrast, the exceedingly low natural abundance of ${ }^{14} \mathrm{C}$ dictates that samples and analyses are conducted "off-line" and require microgram to milligram quantities of carbon. Accordingly, molecular-level ${ }^{14} \mathrm{C}$ analyses presently involve isolation of target compounds prior to their combustion, reduction to graphite, and analysis by accelerator mass spectrometry (AMS).

A key requirement is that the analytes must be isolated in high purity and in sufficient quantity for generating robust, precise ${ }^{14} \mathrm{C}$ data. In this regard, preparative capillary gas chromatography (PCGC) has been found to be an effective tool for isolation of individual compounds for natural abundance ${ }^{14} \mathrm{C}$ analysis (Eglinton et al. 1996). However, while PCGC affords excellent chromatographic resolution of analytes, there are limitations to this approach. The method requires a dedicated instrument and is time consuming. Multiple (often 20-100) consecutive GC cycles are typically required to accumulate sufficient quantities of the target analytes ( $\geq 20 \mu \mathrm{g}$ C) for AMS, even assuming protocols for small-sample ${ }^{14} \mathrm{C}$ analysis are followed (Pearson et al. 1998). Low absolute

\footnotetext{
${ }^{1}$ Department of Marine Chemistry and Geochemistry, Woods Hole Oceanographic Institution, Woods Hole, Massachusetts 02543, USA.

${ }^{2}$ Present address: Institute for Research on Earth Evolution, 2-15 Natsushima-cho, Yokosuka 237-0061, Japan.

${ }^{3}$ Department of Geology and Geophysics, Woods Hole Oceanographic Institution, Woods Hole, Massachusetts 02543, USA.

${ }^{4}$ Corresponding author. Email: teglinton@whoi.edu.
} 
abundances of target analytes often dictate that large quantities of samples may be required to obtain compound-specific ${ }^{14} \mathrm{C}$ data. Lastly, PCGC recoveries dramatically decrease with increasing carbon number for higher carbon number target compounds $\left(>\mathrm{C}_{30}\right)$.

There is, therefore, a need for methods that would enable facile compound isolation and purification while retaining a sufficient level of molecular specificity. In this context, analysis of related suites of compounds (i.e. ${ }^{14} \mathrm{C}$ measurements at the compound class level) offers several advantages. First, the decreased selectivity required for this type of isolation may obviate the need for sophisticated chromatographic separations (i.e. PCGC) without a significant sacrifice in molecular (and hence biological source) specificity. Second, because multiple compounds are pooled to obtain a single sample for ${ }^{14} \mathrm{C}$ analysis, sample size requirements are correspondingly reduced.

One class of compounds that are well suited to streamlined methodologies for ${ }^{14} \mathrm{C}$ analysis are the long-chain $\left(\mathrm{C}_{36}-\mathrm{C}_{39}\right)$ unsaturated ketones-the "alkenones" (Figure 1). Alkenones are produced by a biologically restricted but virtually ubiquitous group of marine algae, particularly the coccolithophores Emiliania huxleyi and Gephyrocapsa oceanica (Volkman et al. 1980; Marlowe et al. 1984). These compounds are generally well preserved in Quaternary marine sediments and serve as excellent molecular stratigraphic tools. They have seen extensive use in paleoceanographic studies due to their utility as proxies of sea surface temperature (SST; Brassell et al. 1986). The SST proxy $U_{37}^{K}$ is based on the relative abundances of di- and tri- unsaturated $\mathrm{C}_{37}$ methyl ketones $\left(U_{37}^{K^{\prime}}=\right.$ $\left.\left[\mathrm{C}_{37: 2}\right] /\left[\mathrm{C}_{37: 2}+\mathrm{C}_{37: 3}\right]\right)$ and is strongly correlated with the temperature of the water in which the algae grow (Prahl and Wakeham 1987). Further interest in alkenone stratigraphy was generated when it was shown that their stable carbon isotopic composition $\left(\delta^{13} \mathrm{C}\right)$ might also be used to estimate paleo$p \mathrm{CO}_{2}$ (Jasper and Hayes 1990; Pagani et al. 1999). Today, alkenones are among the most widely examined organic compounds in marine sediments (Eglinton et al. 2001). The alkenones thus serve as molecular counterparts to microfossil-derived proxies, providing complementary lines of information. While the latter have been targeted for ${ }^{14} \mathrm{C}$ dating in order to derive sediment chronologies and develop age models, alkenone-derived chronologies are now only beginning to be constructed (Ohkouchi et al. 2002; Mollenhauer et al. 2003). The latter is desirable for two reasons: first, it is important to be able to establish age relationships between coexisting foraminifera and molecular species in sediments for accurate interpretation of corresponding proxy records. Second, molecular ${ }^{14} \mathrm{C}$ dating may provide an alternative to microfossil-based ${ }^{14} \mathrm{C}$ chronologies where the latter are impractical (e.g. due to low foraminifera abundances).

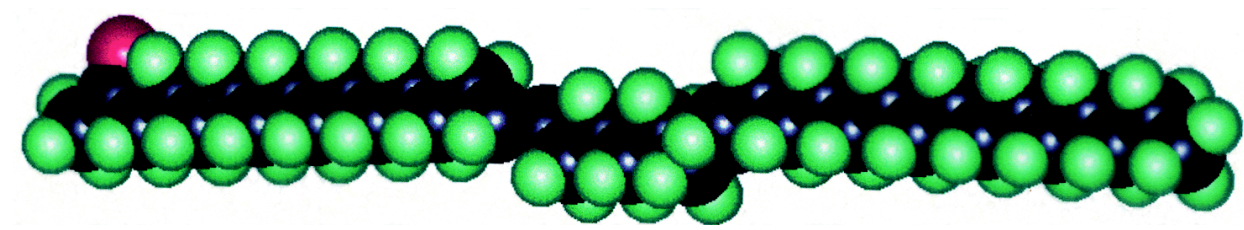

Figure 1 Three-dimensional rendering of a $\mathrm{C}_{37}$ di-unsaturated methyl ketone. Carbon atoms are indicated in black, hydrogen atoms in green, and the oxygen atom in the ketone group in red. Note the trans geometry of the double bonds, which results in a linear molecule.

This paper describes a method for isolation of alkenones as a compound class from marine sediments. The method exploits the unusual structural characteristics of these compounds in order to recover them in high purity. In addition to assessments of purity and yield, the integrity of the unsaturation ratios are also discussed. A separate paper (Mollenhauer et al., this issue) will discuss in detail the evaluation of isotopic compositions obtained using this method. 


\section{EXPERIMENTAL}

\section{Samples}

Marine sediments used in this study are listed in Table 1. They comprise surface or near-surface sediments recovered by box, gravity, or piston corer. They were collected from a wide range of geographical areas including Atlantic, Indian, and Pacific oceans, represent diverse oceanic environments from coastal to pelagic, and have sediment deposition under oxic to anoxic conditions. Abundances of total alkenones in these sediments vary between 0.09 and $1.2 \mu \mathrm{g}$ per gram dry weight $(\mathrm{gdw})$.

Table 1 Estimated total alkenone abundances purified from the sediment samples used in this study.

\begin{tabular}{|c|c|c|c|c|c|c|c|}
\hline \multirow{2}{*}{$\begin{array}{l}\text { Location } \\
\text { Bermuda Rise }\end{array}$} & \multirow{2}{*}{$\frac{\text { Sample ID }}{\text { BC9 } 0-1 \mathrm{~cm}}$} & Latitude & \multirow{2}{*}{$\begin{array}{r}\text { Longitude } \\
57^{\circ} 37^{\prime} \mathrm{W}\end{array}$} & $\begin{array}{l}\text { Depth } \\
(\mathrm{m})\end{array}$ & $\begin{array}{l}U_{37}^{K^{\prime}} \\
\text { FID }^{\mathrm{a}} \\
\text { off-line }\end{array}$ & $\mathrm{C}$ amou & at $(\mu \mathrm{g} \mathrm{C})$ \\
\hline & & $33^{\circ} 42^{\prime} \mathrm{N}$ & & 4517 & 0.577 & 87.0 & 104 \\
\hline & BC9 $1-2 \mathrm{~cm}$ & & & & 0.525 & 75.8 & 82.8 \\
\hline & BC9 $2-3 \mathrm{~cm}$ & & & & 0.496 & 138 & 133 \\
\hline & BC9 $4-6 \mathrm{~cm}$ & & & & 0.676 & n.d & 69.0 \\
\hline & BC9 9-11 cm & & & & 0.847 & 78.6 & 98.9 \\
\hline & BC9 $21-23 \mathrm{~cm}$ & & & & 0.711 & 104 & 125 \\
\hline & GGC5 $192-206 \mathrm{~cm}$ & $33^{\circ} 42^{\prime} \mathrm{N}$ & $57^{\circ} 35^{\prime} \mathrm{W}$ & 4550 & 0.614 & 152 & 137 \\
\hline & GGC5 $282-292 \mathrm{~cm}$ & & & & 0.615 & 152 & 146 \\
\hline & GGC5 $350-360 \mathrm{~cm}$ & & & & 0.622 & 74.3 & 82.8 \\
\hline & GPC5 $345-355 \mathrm{~cm}$ & $33^{\circ} 41^{\prime} \mathrm{N}$ & $57^{\circ} 37^{\prime} \mathrm{W}$ & 4583 & 0.649 & 249 & 258 \\
\hline & GPC5 907-912 cm & & & & 0.695 & 81.1 & 88.8 \\
\hline & GPC5 $1244-1260 \mathrm{~cm}$ & & & & 0.593 & 270 & 290 \\
\hline \multirow[t]{6}{*}{ Santa Barbara Basin } & Pulse-32 $0-1 \mathrm{~cm}$ & $34^{\circ} 14^{\prime} \mathrm{N}$ & $120^{\circ} 04^{\prime} \mathrm{W}$ & 595 & 0.528 & 53.9 & 68.4 \\
\hline & OXMZ $0-0.5 \mathrm{~cm}$ & $34^{\circ} 14^{\prime} \mathrm{N}$ & $120^{\circ} 04^{\prime} \mathrm{W}$ & 595 & 0.477 & 308 & n.d. \\
\hline & OXMZ 2-3 cm & & & & 0.514 & 295 & 313 \\
\hline & OXMZ 6-6.5 cm & & & & 0.505 & 313 & 316 \\
\hline & OXMZ 7-8 cm & & & & 0.502 & 244 & 268 \\
\hline & OXMZ $25-26 \mathrm{~cm}$ & & & & 0.528 & 342 & n.d. \\
\hline Emerald Basin & MC29 $19-20 \mathrm{~cm}$ & $45^{\circ} 53^{\prime} \mathrm{N}$ & $62^{\circ} 48^{\prime} \mathrm{W}$ & 249 & 0.352 & n.d. & 307 \\
\hline \multirow[t]{2}{*}{ Arabian Sea } & $6 \mathrm{BC} 0-2 \mathrm{~cm}$ & $17^{\circ} 49^{\prime} \mathrm{N}$ & $57^{\circ} 30^{\prime} \mathrm{E}$ & 747 & 0.952 & n.d. & 662 \\
\hline & KH89-2 St. 17 surface & $15^{\circ} 00^{\prime} \mathrm{N}$ & $60^{\circ} 00^{\prime} \mathrm{E}$ & 4110 & 0.946 & 375 & 370 \\
\hline Gulf of Mexico & BC6 $0-5 \mathrm{~cm}$ & $28^{\circ} 60^{\prime} \mathrm{N}$ & $89^{\circ} 90^{\prime} \mathrm{W}$ & 365 & 0.875 & 385 & 409 \\
\hline NE Pacific Station & M $0-2 \mathrm{~cm}$ & $34^{\circ} 50^{\prime} \mathrm{N}$ & $123^{\circ} 00^{\prime} \mathrm{W}$ & 4100 & 0.506 & 322 & 340 \\
\hline NW Atlantic & Mud patch surface & $40^{\circ} 30^{\prime} \mathrm{N}$ & $70^{\circ} 45^{\prime} \mathrm{W}$ & 75 & 0.509 & n.d. & 559 \\
\hline
\end{tabular}

aFID = flame ionization detector.

\section{Analytical Procedure}

Figure 2 illustrates a flow chart of the analytical procedure. Air-dried sediments (100-534 gdw) were Soxhlet-extracted with $\mathrm{MeOH} / \mathrm{CH}_{2} \mathrm{Cl}_{2}(3: 7, \mathrm{v} / \mathrm{v})$ for 72 to $168 \mathrm{hr}$. After the resulting total lipid extracts were concentrated to $\sim 5 \mathrm{~mL}$ by rotary evaporation $\left(40^{\circ} \mathrm{C}\right)$, they were transferred to a $40-\mathrm{mL}$ vial and saponified using $0.5 \mathrm{M} \mathrm{KOH} / \mathrm{MeOH}\left(10 \mathrm{~mL}, 100{ }^{\circ} \mathrm{C}, 2 \mathrm{hr}\right)$. The potassium hydroxide (certified ACS grade) was purchased from Fisher Scientific. The saponified products were concentrated to $\sim 3 \mathrm{~mL}$ by a rotary evaporator after which $10 \mathrm{~mL} \mathrm{H}_{2} \mathrm{O}$ was added. A neutral lipid fraction was obtained by liquid-liquid extraction (hexane, $3 \times 10 \mathrm{~mL}$ ) and was subsequently separated into 3 fractions by silica gel (200-400 mesh; BioRad) column chromatography ( $1 \%$ de-activated, $6 \mathrm{~mm}$ i.d. 
$\times 4 \mathrm{~cm}$ ). Hydrocarbon (F1), ketone and aldehyde (F2), and alcohol and sterol (F3) fractions were eluted with $4 \mathrm{~mL}$ hexane, $4 \mathrm{~mL}$ hexane/ $\mathrm{CH}_{2} \mathrm{Cl}_{2}\left(1: 2\right.$, v/v), and $4 \mathrm{~mL} \mathrm{CH}_{2} \mathrm{Cl}_{2} / \mathrm{MeOH}(95: 5$, v/v), respectively.

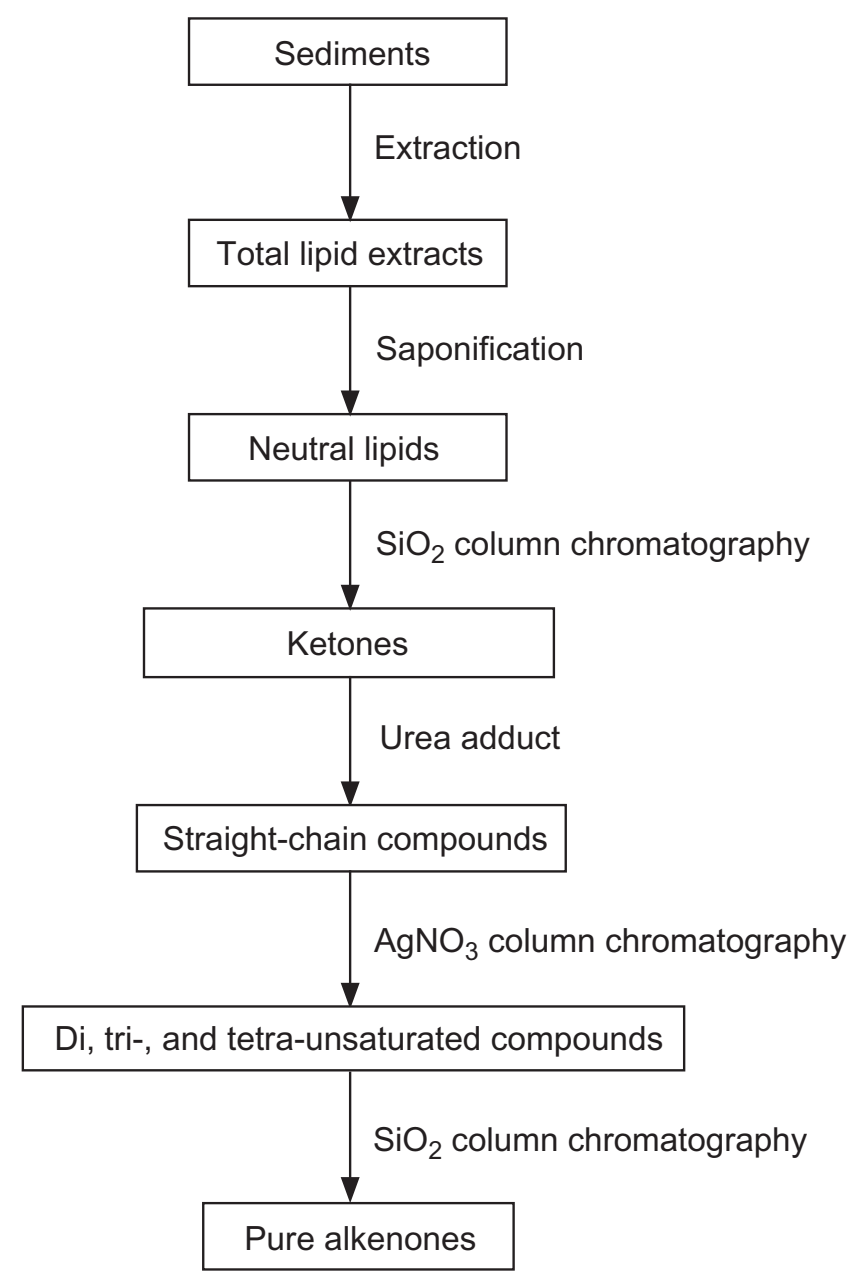

Figure 2 Analytical scheme for purification of alkenones from sediments

Urea adduction was performed on the F2 fraction to remove branched, cyclic, and cis configuration unsaturated compounds (Marlowe et al. 1984). A urea (electrophoresis grade; Fisher Scientific) solution in $\mathrm{MeOH}(40 \mathrm{mg} / \mathrm{mL}, 1.5 \mathrm{~mL})$ was added dropwise to the fraction dissolved in hexane/ $\mathrm{CH}_{2} \mathrm{Cl}_{2}(2: 1, \mathrm{v} / \mathrm{v}, 4.5 \mathrm{~mL})$ in a $40-\mathrm{mL}$ test tube. The tube was cooled $\left(7^{\circ} \mathrm{C}, 15 \mathrm{~min}\right)$ and dried under $\mathrm{N}_{2}$ before a second addition of hexane/ $\mathrm{CH}_{2} \mathrm{Cl}_{2}$ solution $(2: 1, \mathrm{v} / \mathrm{v}, 4.5 \mathrm{~mL})$ and brief agitation using a vortex mixer. The above procedure was repeated 3 times. The sample was then dried under $\mathrm{N}_{2}$, and the precipitated urea crystals were washed with hexane $(2 \times 10 \mathrm{~mL})$ to remove non-adducted compounds. Adducted compounds (including the alkenones) were recovered after the urea crystals were dissolved in $\mathrm{H}_{2} \mathrm{O}(10 \mathrm{~mL})$ and extracted into hexane $(2 \times 10 \mathrm{~mL})$.

Argentation $\mathrm{SiO}_{2}$ column $\left(\mathrm{Ag}^{+} \mathrm{SiO}_{2}\right)$ chromatography was used to separate saturated from unsaturated compounds (Morris 1966). Silver nitrate (10 g; 99.995\%; Aldrich Chemical Co.) was dissolved 
in $\mathrm{MeOH} / \mathrm{H}_{2} \mathrm{O}$ (9:1, v/v, $200 \mathrm{~mL}$ ), and silica gel (100 g; 230-400 mesh; Whatman) was added. After solvent was removed, the $\mathrm{AgNO}_{3}$-impregnated $\mathrm{SiO}_{2}$ gel was further dried in an oven at $50{ }^{\circ} \mathrm{C}$ and then activated at $110^{\circ} \mathrm{C}$ for $48 \mathrm{hr}$. The urea adduct was separated into 3 fractions by $\mathrm{Ag}^{+} \mathrm{SiO}_{2}$ chromatography $(6 \mathrm{~mm}$ i.d. $\times 4 \mathrm{~cm})$. Saturated and mono-unsaturated compounds (G1), di-, tri-, and tetra-unsaturated compounds including the alkenones (G2), and more highly unsaturated compounds (G3) were eluted with $\mathrm{CH}_{2} \mathrm{Cl}_{2}(6 \mathrm{~mL}), \mathrm{CH}_{2} \mathrm{Cl}_{2} / \mathrm{MeOH}$ (9:1, v/v, $\left.4 \mathrm{~mL}\right)$, and $\mathrm{MeOH}(4 \mathrm{~mL})$, respectively.

Immediately before the samples were transferred to quartz tubes ( $9 \mathrm{~mm}$ i.d.) for combustion, $\mathrm{SiO}_{2}$ or $\mathrm{Al}_{2} \mathrm{O}_{3}$ column chromatography was performed to remove any impurities entrained during sample workup.

All organic solvents used in this study were "GC resolved grade" and purchased from Fischer Scientific. All glassware was combusted at $450{ }^{\circ} \mathrm{C}$ for $8 \mathrm{hr}$ and carefully rinsed several times with both $\mathrm{MeOH}$ and $\mathrm{CH}_{2} \mathrm{Cl}_{2}$ immediately before use.

\section{High-Performance Liquid Chromatography}

For certain samples, fractions obtained after urea adduction were processed by semi-preparative high-performance liquid chromatography (HPLC) to isolate specific alkenones or groups of alkenones using a method modified after Xu et al. (2001). An Agilent 1100 series HPLC system was used to separate the alkenones. Samples were separated on a Waters Xterra MS $\mathrm{C}_{18}$ column $(3.0 \times 150 \mathrm{~mm}, 3.5 \mathrm{~m})$ under isocratic conditions using acetonitrile/dicloromethane (82:18) as eluent $(0.50 \mathrm{~mL} / \mathrm{min})$. The system was coupled with an evaporative light scattering detector (ELSD, Sedex 75). The temperature of drift tubing of the detector was $30{ }^{\circ} \mathrm{C}$, and nitrogen pressure was 3 bar. Five percent of the column flow was diverted to the ELSD using a T-splitter. The remainder was available for collection as discrete fractions.

\section{Gas Chromatography}

Gas chromatographic analyses were performed on a Hewlett-Packard Model 5890 II gas chromatograph (GC) equipped with an HP 7673 injector, Gerstel CIS-3 inlet, DB-1 column $(60 \mathrm{~m} \times 0.32 \mathrm{~mm}$ i.d., film thickness $0.25 \mu \mathrm{m}, \mathrm{J} \& \mathrm{~W}$ Scientific), and flame ionization detector (FID). Helium was used as a carrier gas in constant-flow mode $(2 \mathrm{~mL} / \mathrm{min})$. The initial GC oven temperature was $40{ }^{\circ} \mathrm{C}$ and after $1 \mathrm{~min}$ the temperature was raised to $120^{\circ} \mathrm{C}$ at a rate of $30^{\circ} \mathrm{C} / \mathrm{min}$, followed by a second increase to $320^{\circ} \mathrm{C}$ at $6{ }^{\circ} \mathrm{C} / \mathrm{min}$. It was then held at $320^{\circ} \mathrm{C}$ for $25 \mathrm{~min}$. Quantification of alkenones was achieved by comparison of peak area with those of authentic standards (behenic acid myristyl ester [m.w. = 537] and behenic acid palmityl ester [m.w. = 565]; Aldrich Chemical Co.), which were independently injected before the samples. To confirm alkenone purities and to identify interfering components, $\mathrm{GC} / \mathrm{mass}$ spectrometry (GC/MS) analyses were performed for representative samples on a HP6890 GC interfaced to a HP5973 mass selective detector. The DB-5 column $(60 \mathrm{~m} \times 0.32$ $\mathrm{mm}$ i.d., film thickness $0.25 \mu \mathrm{m}$, J\&W Scientific) was temperature programmed using identical conditions to those for GC.

\section{Combustion of Alkenones}

Purified alkenones were transferred to precombusted quartz tubes using $\mathrm{CH}_{2} \mathrm{Cl}_{2}$. After solvents were carefully removed under a stream of $\mathrm{N}_{2}$, precombusted $\mathrm{CuO}(\sim 100 \mathrm{mg})$ was added. The quartz tubes were then evacuated, sealed, and heated to $850{ }^{\circ} \mathrm{C}$ for $5 \mathrm{hr}$. The resulting $\mathrm{CO}_{2}$ was purified by cryogenic distillation, then quantified by manometric techniques (McNichol et al. 1994). 


\section{RESULTS AND DISCUSSION}

The alkenones exhibit several distinct structural features (Figure 1) that we have exploited in devising this step-wise purification/isolation scheme. In particular, the unusual trans double bond configuration, which results in a linear structure, allows the compounds to be occluded within the urea lattice while other branched and cyclic compounds and unsaturated cis configuration lipids are excluded. The method itself is a modification of techniques used to isolate and characterize a novel $\mathrm{C}_{36}$ alkenone in Black Sea sediments (Xu et al. 2001), which in turn is based on that described by Rechka and Maxwell (1988).

Figure 3 shows representative gas chromatograms of fractions obtained during different steps of the purification of alkenones from an Arabian Sea sediment sample (KH89-2 St.17). The F2 fraction obtained after $\mathrm{SiO}_{2}$ chromatography (Figure 3a) contains several large early eluting peaks in addition to the alkenones. These include isoprenoidal ketones, a series of saturated $n$-ketones and $n$-aldehydes, and other unidentified components. After urea clathration, the major peaks in the GC trace of the adduct, other than the alkenones, are a homologous series of straight-chain saturated ketones and aldehydes (Figure 3b). The latter likely have a terrestrial higher plant origin (Prahl and Pinto 1987) and as such would significantly interfere with attempts to determine the isotopic composition of the alkenones. $\mathrm{Ag}^{+} \mathrm{SiO}_{2}$ chromatography (G2 fraction; Figure 3c) greatly reduces the number and abundance of interfering components, leaving the alkenones as the only major peaks remaining in the chromatograms. The final $\mathrm{SiO}_{2}$ chromatographic step is designed to remove any components entrained during the purification procedure (Figure 3d). Most samples contain a small amount of $\mathrm{C}_{36}$ alkenone as well as the more commonly reported $\mathrm{C}_{37}-\mathrm{C}_{39}$ alkenones (Xu et al. 2001). Samples from the Santa Barbara Basin, northwest Pacific, and northeast Atlantic also contain a compound that is tentatively identified as a $\mathrm{C}_{35}$ alkenone based on the GC retention characteristics (Xu et al. 2001).

\section{Purity}

It is apparent from the above results that the procedure employed successfully removes most GCamenable components, except for the target compounds. In most cases, the sum of the areas of impurity peaks in the final GC/FID chromatograms were $<2 \%$ of those due to the total alkenones. To assess the potential impact on ${ }^{14} \mathrm{C}$ data, we can assume as a worst case that the alkenones are modern age (i.e. $\Delta^{14} \mathrm{C}^{5}=0 \%$ ) and interfering peaks are infinite in age $\left(-1000 \%\right.$ ). The ${ }^{14} \mathrm{C}$ offset in alkenone ages corresponds to $160 \mathrm{yr}\left(-40 \%\right.$ ) or less, which is greater than the measurement error for ${ }^{14} \mathrm{C}$ but adequate for many applications. Potential contributions from non-GC amenable components (e.g. higher boiling or more polar compounds, or particulate organic carbon that does not elute under the GC conditions employed) were assessed by comparison of both carbon abundances and stable carbon isotopic compositions $\left(\delta^{13} \mathrm{C}\right)$ of purified alkenone samples before and after sealed tube combustion (Eglinton et al. 1996). Carbon abundances determined from GC/FID peak area integration are contrasted with those from manometric determination of $\mathrm{CO}_{2}$ yields after combustion in Figure 4. Overall, the carbon yields estimated from $\mathrm{CO}_{2}$ gas evolved by combustion are in good agreement with those independently determined by summed, integrated, and calibrated GC/FID peak areas of the total alkenones $\left(r^{2}=0.989, n=18\right)$. Closer inspection reveals that $\mathrm{CO}_{2}$ yields of some samples are up to $10 \%$ higher than those estimated by FID response (Figure 4). Some of this discrepancy could be caused by errors associated with analysis by GC/FID. For example, repeated $(n=9)$ injections of the $\mathrm{C}_{19}$ ketone standard resulted in a standard deviation $(1 \sigma)$ of $9.4 \%$ for corresponding $\mathrm{GC} /$

${ }^{5} \Delta^{14} \mathrm{C}=\left(f_{m} e^{-\lambda(\mathrm{y}-1950)}-1\right) * 1000$, where $\lambda=1 / 8267\left(\mathrm{yr}^{-1}\right) ; f_{m}=$ fraction modern ${ }^{14} \mathrm{C}$, corrected for isotopic fractionation using $\delta^{13} \mathrm{C}$; and $y$ is the year of sample collection. 


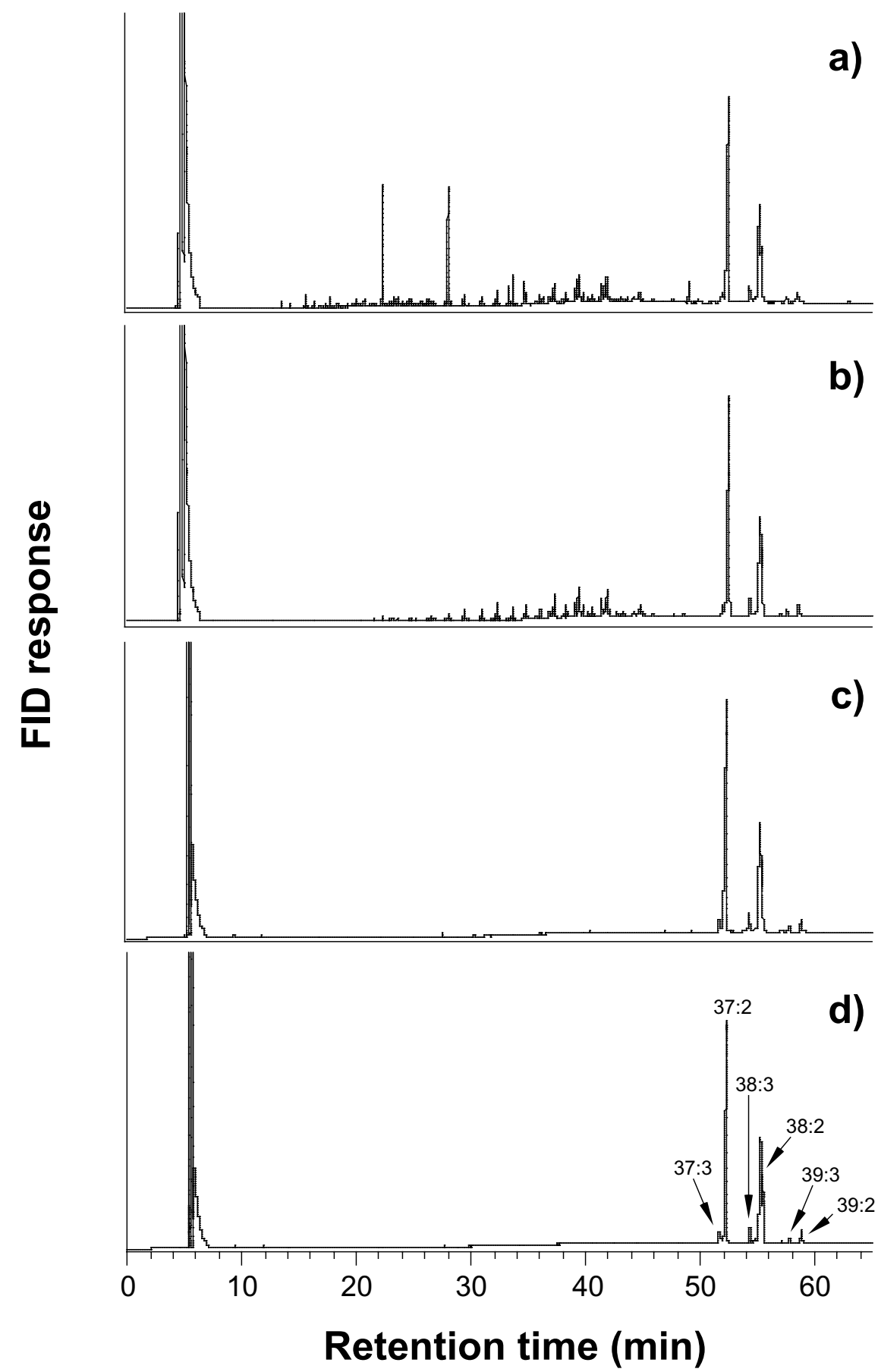

Figure 3 GC/FID traces along the purification steps of Arabian Sea sediments (KH89-2 St. 17): a) ketone fraction (F2) by silica gel column chromatography; b) urea adducted fraction; c) di-, tri-, and tetra-unsaturated compound fraction (G2) of silver nitrate-silica gel column chromatography; and d) ketone fraction (F2) of final silica gel column chromatography. 
FID of peak area. However, a linear regression line is slightly above the 1:1 line (Figure 4), suggesting that the $\mathrm{CO}_{2}$ yields are systematically higher than those expected from total alkenone abundances based on GC/FID measurements. Moreover, samples with higher-than-expected combustion yields were not necessarily those containing the lowest amount of alkenones. Thus, although part of the difference could be explained by a combustion blank that on average contains $\sim 1 \mu \mathrm{g} C$ (Pearson et al. 1998), the remainder may be explained by compounds that were not removed by our procedure. Although the abundance of impurities will partly depend on sample type, we conclude that the purity of alkenones is typically significantly greater than $90 \%$ and that purity is likely to be $>95 \%$ if alkenone abundances are $>100 \mu \mathrm{g} \mathrm{C}$.

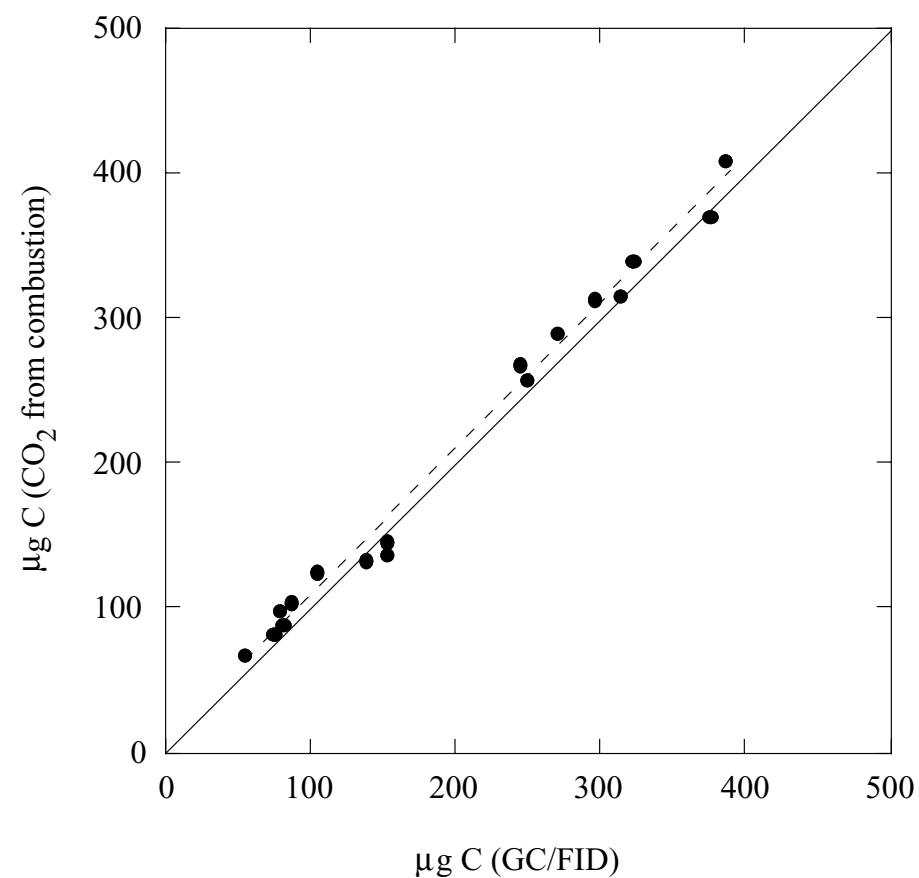

Figure 4 Comparison of $\mathrm{CO}_{2}$ yield (as $\mu \mathrm{g} \mathrm{C}$ ) after combustion of purified alkenones and carbon amount of total $\left(\mathrm{C}_{36}-\mathrm{C}_{39}\right)$ alkenones estimated from GC/FID measurements. Dashed and solid lines represent a linear regression line for the plot and a 1:1 line, respectively.

\section{Recovery}

We calculated the total yield of $\mathrm{C}_{36}-\mathrm{C}_{39}$ alkenones from corresponding GC/FID peak areas during each step of purification procedure. Based on these values, we estimated overall recovery through the entire procedure averages $71 \%$, whereas average recovery for urea adduction, $\mathrm{Ag}^{+} \mathrm{SiO}_{2}$ chromatography, and final $\mathrm{SiO}_{2}$ chromatography steps are $97 \%, 82 \%$, and $87 \%$, respectively (Figure 5a). We should note that the variability in recoveries of alkenones $(1 \sigma)$ is relatively large: $17 \%$ for urea adduction, $11 \%$ for $\mathrm{Ag}^{+} \mathrm{SiO}_{2}$ chromatography, and $17 \%$ for final $\mathrm{SiO}_{2}$ chromatography. Thus, a major part of alkenone loss occurred during silver nitrate-silica gel column chromatography. Since in most cases we found no detectable alkenones in other fractions (G1 and G3 fractions) from this step, we suspect this loss of may be caused by oxidation of double bonds and conversion of alkenones to other products that do not elute from the $\mathrm{Ag}^{+} \mathrm{SiO}_{2}$ column or are not amenable to GC. 

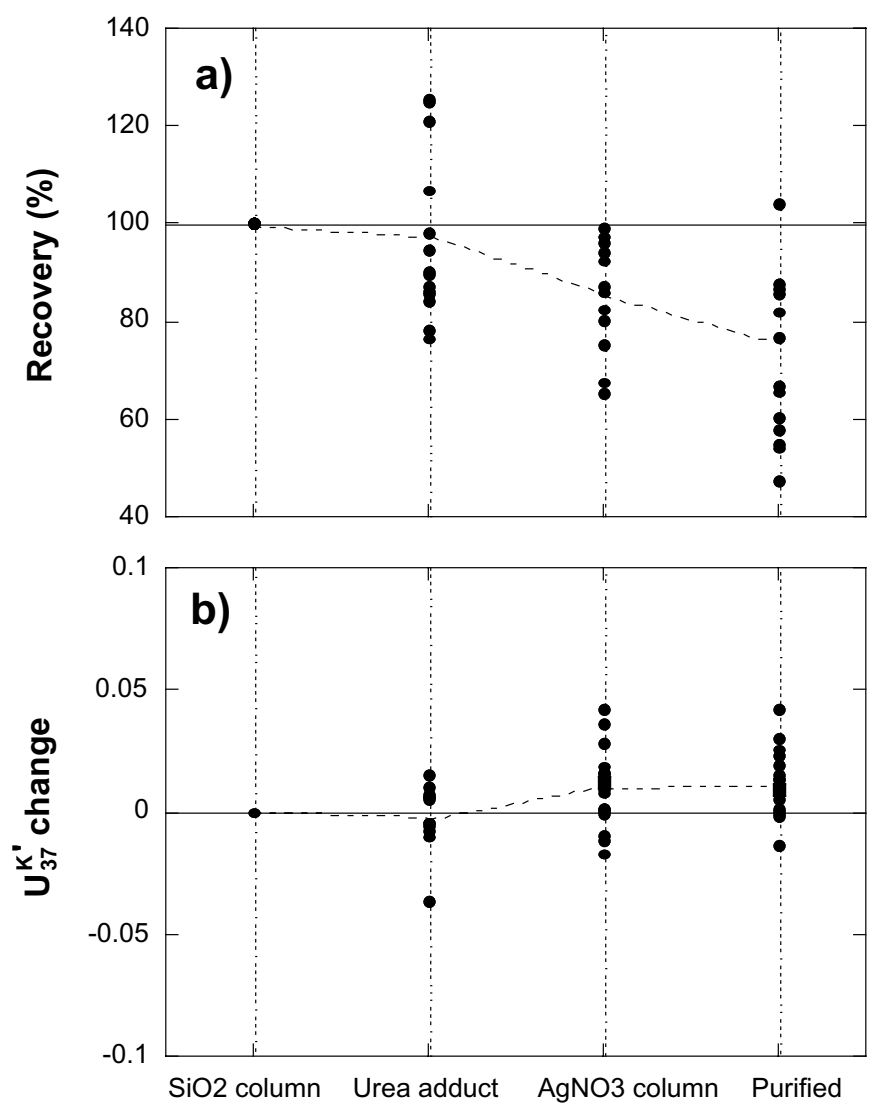

\section{Procedure}

Figure 5 Variation of a) recovery and b) $U_{37}^{K^{\prime}}$ values along the purification steps. Broken lines connect mean value of each step. $U_{37}^{K^{\prime}}=\left[\mathrm{C}_{37: 2}\right] /\left(\left[\mathrm{C}_{37: 2}\right]+\left[\mathrm{C}_{37: 3}\right]\right)$, where $\left[\mathrm{C}_{37: 2}\right]$ and $\left[\mathrm{C}_{37: 3}\right]$ indicate concentrations of di- and tri-unsaturated $\mathrm{C}_{37}$ alkenones, respectively.

\section{Integrity of $\mathbf{U}_{37}^{\mathbf{K}^{\prime}}$ Values}

We also monitored potential variations in the degree of unsaturation of the alkenones $\left(U_{37}^{K^{\prime}}\right)$ (Brassell et al. 1986; Prahl and Wakeham 1987) of several samples during the course of the purification procedure (Figure 5b). Average changes in $U_{37}^{K^{\prime}}$ values for urea adduction, $\mathrm{Ag}^{+} \mathrm{SiO}_{2}$ chromatography, and final $\mathrm{SiO}_{2}$ chromatography steps are $-0.001,0.010$, and 0.012 units, respectively. In the urea adduction step, no clear systematic shift of $U_{37}^{K}$ was observed, even though some compounds which coeluted with both $\mathrm{C}_{37: 2}$ and $\mathrm{C}_{37: 3}$ alkenone peaks were removed by this step. The slight increase of $U_{37}^{K^{\prime}}$ after $\mathrm{Ag}^{+} \mathrm{SiO}_{2}$ chromatography may be caused by removal of small unidentified peaks coeluting with the $\mathrm{C}_{37: 3}$ alkenone (Xu et al. 2001). In the final $\mathrm{SiO}_{2}$ chromatography step, we observed the largest increase in $U_{37}^{K}$ values. The reason for this increase in unclear. We did not find clear relationships between recovery and changes in $U_{37}^{K}$ values in these purification steps. Overall increase of $U_{37}^{K}(0.021$ unit in average) in this alkenone purification procedure corresponds to a $0.62{ }^{\circ} \mathrm{C}$ change in the SST estimate (based on a calibration by Prahl et al. [1988]) and compares favorably with the overall precision of this method $\left( \pm 0.5^{\circ} \mathrm{C}\right.$; Prahl and Wakeham 1987). 


\section{Isolation of Individual Alkenones by HPLC}

Figure 6 shows a chromatograph from the HPLC separation of a purified alkenone fraction from a laboratory culture of Isochrysis sp. The chromatographic conditions employed resulted in near complete separation of the alkenone fraction into its individual constituents. Up to $50 \mu \mathrm{g}$ of each alkenone can be separated in a single injection. Ethyl and methyl ketones coelute under these chromatographic conditions. Analyses of Black Sea alkenone fractions using this method also showed that $\mathrm{C}_{36: 2}$ and $\mathrm{C}_{39: 3}$ coelute with $\mathrm{C}_{38: 3}$ and $\mathrm{C}_{37: 2}$ alkenones, respectively. However, the former are typically relatively minor components of sedimentary alkenone mixtures.

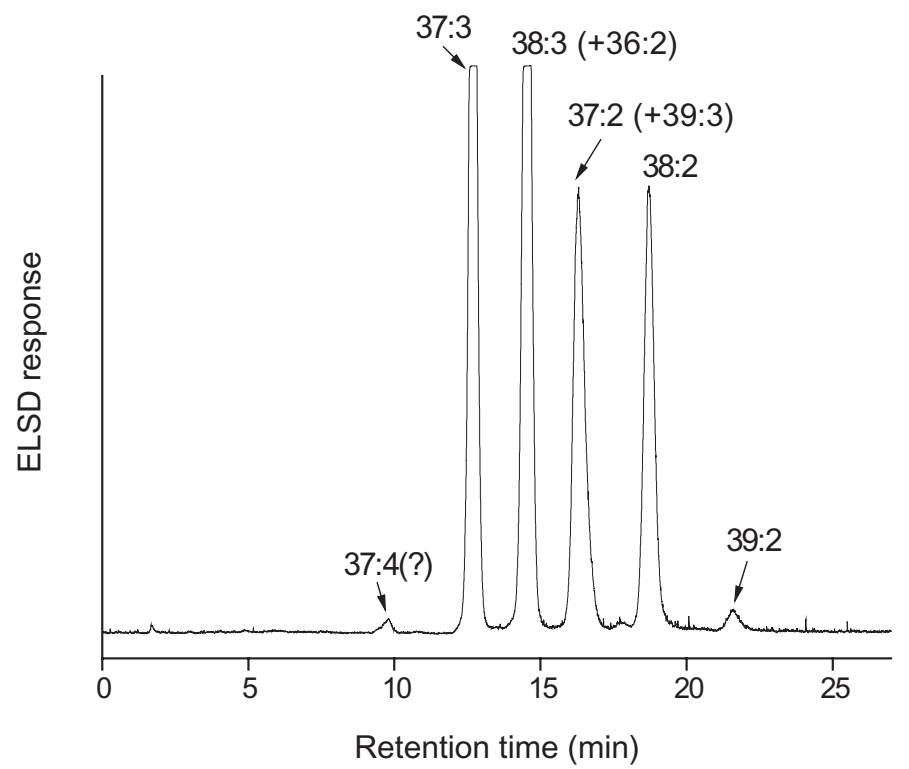

Figure 6 HPLC/ELSD trace from analysis of an alkenone fraction of Black Sea sediments. Peak identifications are based on GC/FID and GC/MS analyses.

Multiple 1-minute-long fractions were collected according to detector response in order to isolate the following compounds: (1) $\mathrm{C}_{37: 3} \mathrm{Me}$; (2) $\mathrm{C}_{38: 3} \mathrm{Et}+\mathrm{C}_{38: 3} \mathrm{Me}+\mathrm{C}_{36: 2} \mathrm{Et}$; (3) $\mathrm{C}_{37: 2} \mathrm{Me}+\mathrm{C}_{39: 3} \mathrm{Et}$; (4) $\mathrm{C}_{38: 2} \mathrm{Et}+\mathrm{C}_{38: 2} \mathrm{Me}$; and (5) $\mathrm{C}_{39}$ : $\mathrm{Et}$; where $M e$ and $E t$ refer to methyl and ethyl ketones, respectively. Figure 7 shows GC/FID traces corresponding to the first 4 fractions. In each case, the HPLC fractions yield relative pure compounds with only minor interference from alkenones that closely elute on the HPLC trace. Estimated purities of alkenones isolated using this method are typically better than $98 \%$.

\section{CONCLUSIONS}

The method described here is capable of isolating alkenones in high purity from complex mixtures of organic compounds present in ocean sediments recovered from various depositional environments. This method allows batch processing of samples, thereby substantially reducing the time required for purification of alkenones compared with methods based on PCGC. This new method could be useful for measuring not only ${ }^{14} \mathrm{C}$ and stable carbon isotopic abundances in alkenones but also for purification of these compounds for determination of other isotopic compositions (e.g. D/H or ${ }^{18} \mathrm{O} /{ }^{16} \mathrm{O}$ ). HPLC separation of the purified alkenone fractions allows isolation of individual alkenones for further characterization. This procedure may be used, for example, to produce an alkenone standard that is presently commercially unavailable. 


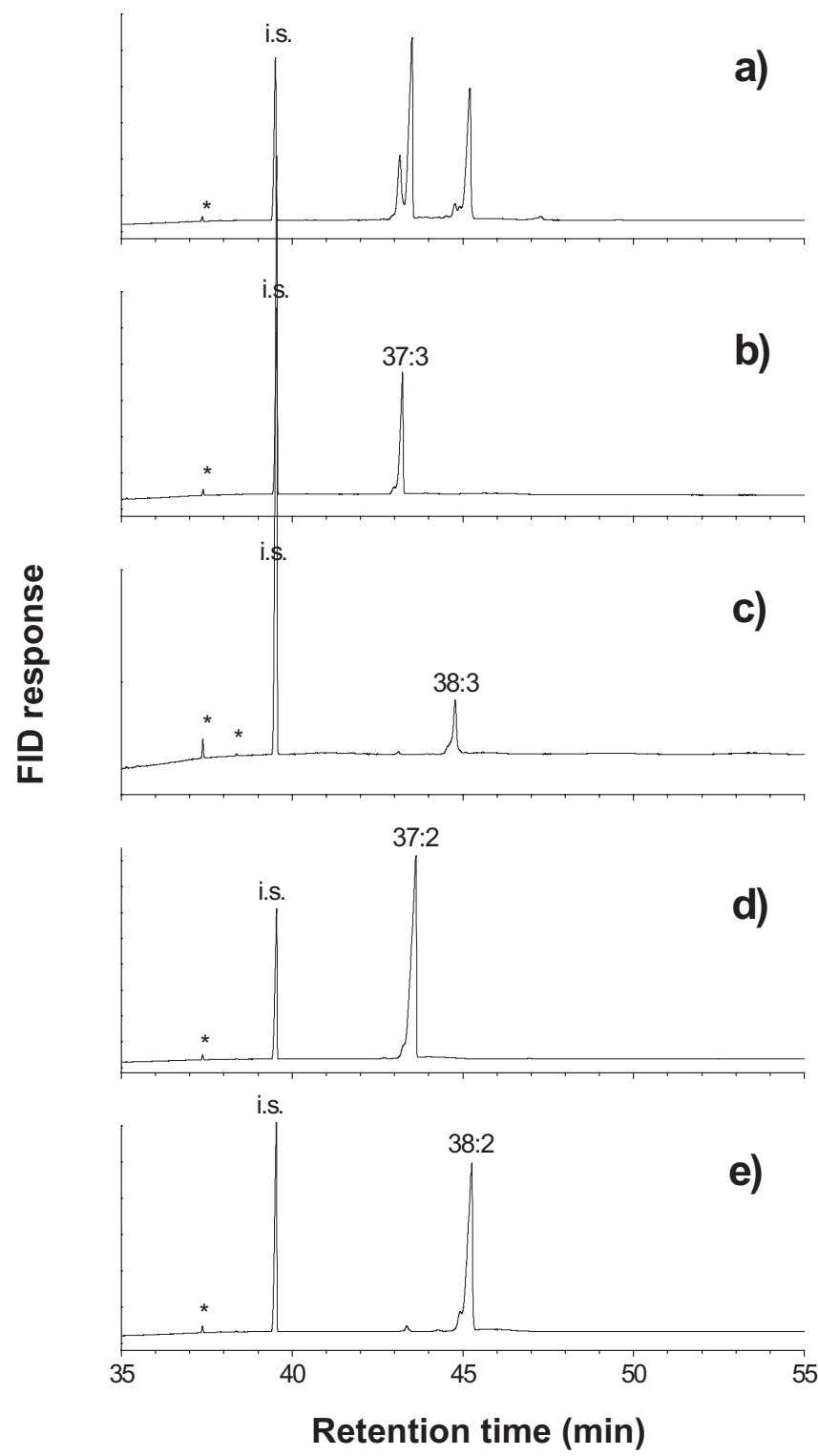

Figure 7 Partial GC/FID traces of alkenones isolated by HPLC from Black Sea sediments: a) initial mixture of alkenones; b) fraction 2 (13-14 min); c) fraction 4 (15-16 $\mathrm{min})$; d) fraction 6 (17-18 $\mathrm{min})$; e) fraction 8 (19-20 $\mathrm{min})$.

\section{ACKNOWLEDGMENTS}

We thank C Johnson, S Sylva, and NOSAMS staff for laboratory assistance; L D Keigwin for providing Bermuda Rise sediments (GPC5); and M Murayama for providing Arabian Sea sediments. We also thank T Herbert for constructive comments on the earlier version of the manuscript. This work was funded through grants from the National Science Foundation (OCE-9809624; OCE9907129) and the Japan Society for the Promotion of Science. 


\section{REFERENCES}

Brassell SC, Eglinton G, Marlowe IT, Pflaumann U, Sarnthein M. 1986. Molecular stratigraphy: a new tool for climatic assessment. Nature 320:129-33.

Eglinton TI, Aluwuihare LI, Bauer JE, Druffel ERM, McNichol AP. 1996. Gas chromatographic isolation of individual compounds from complex matrices for radiocarbon dating. Analytical Chemistry 68:904-12.

Eglinton TI, Benitez-Nelson BC, Pearson A, McNichol AP, Bauer JE, Druffel ERM. 1997. Variability in radiocarbon ages of individual organic compounds from marine sediments. Science 277:796-9.

Eglinton TI, Conte MH, Eglinton G, Hayes JM. 2001. Proceedings of a workshop in alkenone-based paleoceanographic indicators. Geochemistry Geophysics Geosystems 2:doi2000GC000122.

Hayes JM, Freeman KH, Popp BN, Hoham CH. 1990 Compound-specific isotopic analyses: a novel tool for reconstruction of ancient biogeochemical processes. Organic Geochemistry 16:1115-28.

Jasper JP, Hayes JM. 1990. A carbon isotope record of $\mathrm{CO}_{2}$ levels during the late Quaternary. Nature 347: 462-4.

Marlowe IT, Brassell SC, Eglinton G, Green JC. 1984. Long chain unsaturated ketones and esters in living algae and marine sediments. Organic Geochemistry 6: $135-41$.

McNichol AP, Osborne EA, Gagnon AR, Fry B, Jones GA. 1994. TIC, TOC, DIC, DOC, PIC, POC - unique aspects in the preparation of oceanographic samples for ${ }^{14} \mathrm{C}$-AMS. Nuclear Instruments and Methods in Physics Research B 92:162-5.

Mollenhauer G, Eglinton TI, Ohkouchi N, Schneider RR, Muller PJ, Grootes PM, Rullkotter J. 2003. Asynchronous alkenone and foraminifera records from Benguela Upwelling System. Geochimica et Cosmochimica Acta 67:2157-71.

Morris LJ. 1966. Separations of lipids by silver ion chromatography. Journal of Lipid Research 7:717-32.

Ohkouchi N, Eglinton TI, Keigwin LD, Hayes JM. 2002. Spatial and temporal offsets between proxy records in a sediment drift. Science 298:1224-7.

Pagani M, Freeman KH, Arthur MA. 1999. Late Miocene $\mathrm{CO}_{2}$ concentrations and the expansion of $\mathrm{C}_{4}$ grasses.
Science 285:876-9.

Pearson A, McNichol AP, Schneider RJ, von Raden KF. 1998. Microscale AMS ${ }^{14} \mathrm{C}$ measurement at NOSAMS. Radiocarbon 40(1):61-75.

Pearson A, Eglinton TI, McNichol AP. 2000. An organic tracer for surface ocean radiocarbon. Paleoceanography 15:541-50.

Petsch ST, Eglinton TI, Edwards KJ. 2001. ${ }^{14} \mathrm{C}$-dead living biomass: evidence for microbial assimilation of ancient organic carbon during shale weathering. Science 292:1127-31.

Prahl FG, Pinto LA. 1987. A geochemical study of longchain aldehydes in Wahington coast sediments. Geochimica et Cosmochimica Acta 51:1573-82.

Prahl FG, Wakeham SG. 1987. Calibration of unsaturation patterns in long-chain ketone compositions for palaeotemperature assessment. Nature 330:367-9.

Prahl FG, Muehlhausen LA, Zahnle DL. 1988. Further evaluation of long-chain alkenones as indicators of paleoceanographic conditions. Geochimica et Cosmochimica Acta 52:2303-10.

Rechka JA, Maxwell JR. 1988. Characterization of alkenone temperature indicators in sediments and organisms. Organic Geochemistry 13:727-34.

Sauer PE, Eglinton TI, Hayes JM, Schimmelmann A, Sessions AL. 2001. Compound-specific D/H ratios of lipid biomarkers from sediments as a proxy for environmental and climatic conditions. Geochimica et Cosmochimica Acta 65:213-22.

Sessions AL, Burgoyne TW, Schimmelmann A, Hayes JM. 1999. Fractionation of hydrogen isotopes in lipid biosynthesis. Organic Geochemistry 30:1193-200.

Volkman JK, Eglinton G, Corner EDS, Sargent JR. 1980. Novel unsaturated straight-chain $\mathrm{C}_{37}-\mathrm{C}_{39}$ methyl and ethyl ketones in marine sediments and a coccolithophore Emiliania huxleyi. In: Douglas AG, Maxwell JR, editors. Advances in Organic Geochemistry 1979. Oxford: Pergamon. p 219-27.

Xu L, Reddy CM, Farrington JW, Frysinger GS, Gaines RB, Johnson CG, Nelson RK, Eglinton TI. 2001. Identification of a novel alkenone in Black Sea sediments. Organic Geochemistry 32:633-45. 